medRxiv preprint doi: https://doi.org/10.1101/2020.09.01.20186288; this version posted September 3, 2020. The copyright holder for this preprint (which was not certified by peer review) is the author/funder, who has granted medRxiv a license to display the preprint in

It is made available under a CC-BY-NC-ND 4.0 International license.

Noname manuscript No.

(will be inserted by the editor)

\title{
A model assessing potential benefits of isolation and mass testing on COVID-19: the case of Nigeria
}

\author{
Faraimunashe Chirove • Chinwendu E. \\ Madubueze - Zviiteyi Chazuka - Sunday \\ Madubueze
}

Received: date / Accepted: date

\begin{abstract}
We consider a model with mass testing and isolation mimicking the current policies implemented in Nigeria and use the Nigerian daily cumulative cases to calibrate the model to obtain the optimal mass testing and isolation levels. Mathematical analysis was done and important thresholds such the peak size relation and final size relation were obtained. Global stability analysis of the disease-free equilibrium indicated that COVID-19 can be eradicated provided that $\mathcal{R}_{0}<1$ and unstable otherwise. Results from simulations revealed that an increase in mass testing and reduction of transmission from isolated individuals are associated with benefits of increasing detected cases, lowering peaks of symptomatic cases, increase in self-isolating cases, decrease in cumulative deaths and decrease in admissions into monitored isolation facilities in the case of Nigeria.
\end{abstract}

Keywords COVID-19 · Isolation · Mass testing

Mathematics Subject Classification (2010) 92B05 $\cdot 34 \mathrm{~A} 12 \cdot 34 \mathrm{~A} 34$

\footnotetext{
Faraimunashe Chirove

University of Johannesburg, Department of Mathematics and Applied Mathematics, South Africa

E-mail: fchirove@uj.ac.za

Chinwendu E. Madubueze

Federal University of Agriculture, Department of Mathematics, Statistics and Computer Science, Nigeria

Zviiteyi Chazuka

Chinhoyi University of Technology, School of Natural Sciences and Mathematics, Zimbabwe

Sunday Madubueze

Sunday Madubueze

Dalhatu Araf Specialist Hospital, Department of Family Medicine, Lafia, Nigeria.
} 
medRxiv preprint doi: https://doi.org/10.1101/2020.09.01.20186288; this version posted September 3, 2020. The copyright holder for this preprint (which was not certified by peer review) is the author/funder, who has granted medRxiv a license to display the preprint in It is made available under a perpetuity.

perpetuity.

\section{Introduction}

The novel coronavirus disease 2019 (COVID-2019) is the world's recent pandemic. It is a highly contagious disease caused by severe acute respiratory syndrome coronavirus-2 (SARS-CoV-2) $[18,31]$ that belongs to the same family with severe acute respiratory syndrome coronavirus (SARS-CoV), and Middle East respiratory syndrome coronavirus (MERS-CoV) which are known to cause pneumonia in humans $[18,22,2,33]$. The first outbreak in Wuhan, China in December 2019 has since spread to the rest of the world $[2,33,26]$ which saw it being declared a world pandemic in $2020[22,27]$

Currently, there are over 21 million confirmed cases, over 750 thousand deaths and close to 14 million recoveries. Africa alone has over one million confirmed cases, about 24 thousand deaths and about 780 thousand recoveries. Nigeria currently is the third highest contributor to the African burden with about 48 thousand confirmed cases, close to a thousand deaths and over 34 thousand recoveries [35]. The COVID-19 primary source of transmission was firstly suspected to be from wild animals to humans but in Nigeria and the rest of Africa, the primary source was patients infected with COVID-19 travelling into the continent $[18,2,31]$

In general, COVID-19 case fatality is low but people with co-morbidities like diabetes mellitus, cancer, chronic obstructive pulmonary diseases, and hypertension are at high risk of COVID-19 fatalities. The routes of transmission for SARS-CoV-2 are respiratory droplets (generated via sneezing and coughing), close contact with an infected person, contact with environmental surfaces and aerosols. Successful infection by a virus occurs when adequate viral load enters the body, penetrates the target cells, replicates and gets released to infect more cells [18]. The symptoms of COVID-19 illness are fever, dry cough, and fatigue, headache, haemoptysis, diarrhoea, difficulty with breathing and muscular pain $[2,26,25]$. Severe disease is characterised by acute respiratory syndrome, acute cardiac failure, acute kidney failure, anaemia, stroke, multiple organ dysfunction, and secondary bacterial infection [36]. The current preventive methods, among others, are maintaining physical distancing, observing cough etiquette, quarantine, isolation and community lock downs $[33,34]$.

The incubation period of SARS-CoV-2 has been estimated to range from 2 to 14 days [22]. Available evidence showed that COVID-19 human-to-human transmission occurs during the asymptomatic incubation period which is usually 2 to 10 days [27]. This suggests that for any systems to control the infection effectively, the asymptomatic individuals should be subjected to testing so that preventive measures such as self and mandatory isolation can be effected to reduce the spread of the infection. Community mass testing is one of the strategies that can be used to identify infected individuals. Isolation is the separation of persons with contagious disease from those not infected [7]. The infected individuals can be isolated in hospital settings for severe and critical diseases while sub-clinical infections can stay at home. For isolation to be effective in halting transmission, cases should be identified before the onset of viral shedding or at least before the onset of peak viral shedding $[33,14]$. One 
medRxiv preprint doi: https://doi.org/10.1101/2020.09.01.20186288; this version posted September 3, 2020. The copyright holder for this preprint (which was not certified by peer review) is the author/funder, who has granted medRxiv a license to display the preprint in It is made available under a CC-BY-NC-ND 4.0 International license .

of the effective testing instruments is the use of real time polymerase chain reaction (RT-PCR) $[18,3]$ which was used effectively among sheltered people in Boston, USA and South Korea on the asymptomatic population to reduce the risk of community transmissions instead of focusing only on those with severe symptoms or high risk groups [3]. It has been argued that a populationwide mass testing would help identify individuals that are likely to transmit disease long before symptoms appear [28]. Thus, the fight against COVID-19 is a war against an invisible enemy which requires rapid detection of those that can transmit the infection and quickly isolate them before viral shedding commences.

COVID-19 sufferers can be classified into three groups: sub-clinical (asymptomatic and mild symptomatic) infections, severe disease, and critical disease [22]. The first two groups accounts for approximately $81 \%$ of cases and usually resolve without any pharmacologic intervention[22]. They pose serious danger to containment because they can transmit the virus without being aware of their status. This group often refuses isolation from the community and even when isolated, may attempt to escape from the isolation centre and can recover without any intervention. Those with severe disease account for $14 \%$ and would require hospitalization, supportive and pharmacologic therapies while those with critical disease account for the remaining $5 \%$ requiring nursing in the intensive care unit with ventilator [22]. Treatment administration remains largely supportive therapy $[22,10]$.

Our study seeks to assess the potential impact of isolation and mass testing of the population on the transmission of COVID-19 in Nigeria using mathematical modelling approach. We present the background setting for Nigeria henceforth.

\subsection{The Nigeria situation}

Nigeria has a population of 205,416,152 persons as of 14 May 2020 [35]. The Nigeria COVID-19 cases started with an imported case of a 44-year-old Italian citizen who presented himself to the staff clinic on the $26^{\text {th }}$ of February 2020 and was later confirmed as the first official case of COVID-19 in Nigeria on the $27^{\text {th }}$ of February 2020. Contact tracing for the index case identified about 40 asymptomatic who were tested and produced one confirmed positive making it the second case of COVID-19 on the $8^{\text {th }}$ of March 2020. More imported cases were reported in March and since then the infection rose to current aforementioned pandemic levels in Nigeria [21,12].

The first COVID-19 related death was recorded on the $22^{\text {nd }}$ of March 2020 and the fatality was due to co-morbidities complications. Cumulative confirmed cases in Figure 1 are used for calibration of the mathematical model. The lock down was announced by Nigeria Government effected measures such as travel bans from his risk countries and as well as lock down in order to halt the community spread of the COVID-19. The initial lock down was in Lagos, Abuja, and Ogun states on the $30^{t h}$ of March 2020 and later extended to other 
medRxiv preprint doi: https://doi.org/10.1101/2020.09.01.20186288; this version posted September 3, 2020. The copyright holder for this preprint (which was not certified by peer review) is the author/funder, who has granted medRxiv a license to display the preprint in

It is made available under a CC-BY-NC-ND 4.0 International license .

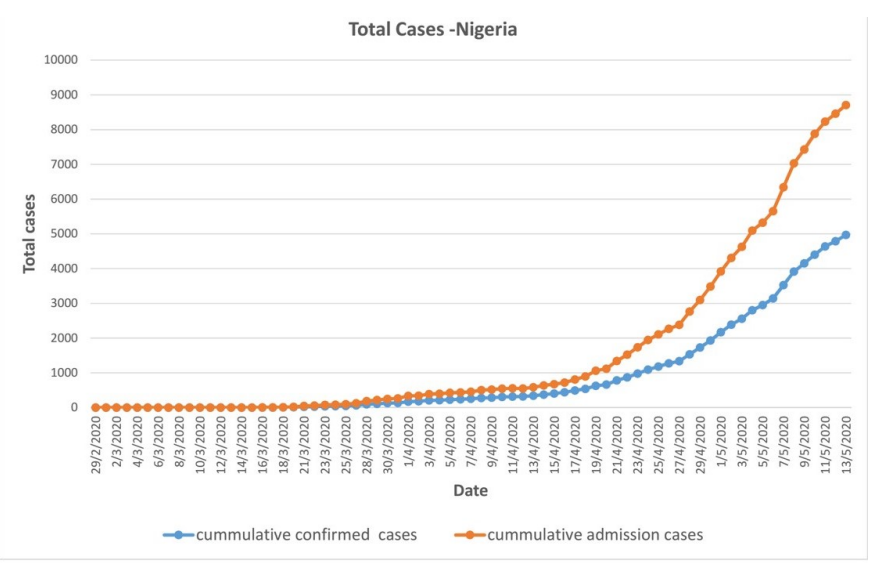

Fig. 1 Cumulative cases in Nigeria

states. Subsequent easing of lock down measures ushered in new measures including mandatory wearing of face masks, nationwide night-time curfew and a ban on non-essential travelling between different states of the country being enforced [1]. Mass testing is yet to take effect in Nigeria. As of 22 August 2020, Nigeria has carried out 374,077 sample tests which is small for a country with over 200 million people [11]. This poor testing capacity makes the epidemic curve not flatten in Nigeria. Nigeria has about 61 laboratories for COVID19 testing. The testing is for three categories of people, those with travelling history outside Nigeria and symptoms within 14 days of arrival, those with contact with confirmed case and symptoms, and those with symptoms and stay in high prevalence of COVID-19 area in Nigeria. [11,30]

\subsection{Mathematical modelling of COVID-19}

A number of mathematical models for COVID-19 have so far been established which looked at the different effects of intervention strategies and predict the probable outcomes of the pandemic. The Studies presented in $[6,20,15,32,9$, $19,16,24,23,8]$ used the standard SEIR compartmental structure to model the various aspects of COVID-19 dynamics interventions. However, the studies in $[5,17]$ points out the inadequacy of the framework and presented improved frameworks which included the quarantined classes as well as the dead compartments. The results from all the aforementioned studies focused on the benefits of control measures such as quarantining, travel restrictions and social distancing, among others but did not take into consideration the effects of the asymptomatic infectious individuals as these are one of the major undetected cases that are drivers of infection. To detect this group of individuals, measures such as mass testing and isolation will need to be implemented. Checchi et al. [8] presented a discrete time age structured mathematical model for the spread of COVID-19 in African settings looking at the effects of isolation, 
social distancing and shielding in the reduction of COVID-19 cases in Africa using data from Mauritius, Nigeria and Niger. They concluded that isolation and social distancing were effective when subjected to lock down conditions. Our current work on the dynamics of the novel COVID-19 virus in Nigeria uses a deterministic modelling approach to estimate the potential impact of self and mandatory isolation, and mass testing. The organisation of the paper is as follows: in section 2 we present the model formulation of our deterministic mathematical model for COVID-19 dynamics in Nigeria, section 3 presents fundamental properties of the model, threshold computation and equilibrium stability analysis.

\section{Materials and Methods}

We formulate a mathematical model to study the dynamics COVID-19 incorporating mass testing and, self and mandatory isolation. We consider a homogeneously mixing population that comprises of the following compartments: the susceptible population $S(t)$, the exposed population with the virus but not yet able to transmit it to other individuals $E(t)$, infectious asymptomatic population not yet tested $I_{A}(t)$, infectious asymptotic population that has been tested and self isolating $I_{A T}(t)$, infectious symptomatic population $I_{s}(t)$, infectious symptomatic isolated population under health care enclosures and monitoring $J(t)$ and the removed population $R(t)$. We assume that mass testing mostly affects those in classes $I_{A}(t), I_{s}(t)$ mainly because these are the only classes where individuals test positive. Individuals in $S(t)$ and $E(t)$ and $R(t)$ will test negative and thus, will remain in the same class as the ones untested. Individuals in $I_{s}(t)$ as soon as they test positive are immediately transferred into isolation centres and hence, are assumed not to self isolate. The total human population $N(t)$ is

$$
N(t)=S(t)+E(t)+I_{A}(t)+I_{A T}(t)+I_{s}(t)+J(t)+R(t) .
$$

Since COVID-19 is a respiratory, we leave out the demographic parameters and concentrate on the infection and intervention dynamics due to differences in time scales of occurrence between demographic and infection dynamics. The force of infection for the model is assumed to be

$$
\lambda=\frac{\beta\left[I_{s}+\eta_{1} I_{A}+\eta_{2} I_{A T}+\eta_{3} J\right]}{N},
$$

where $\beta$ is the effective transmission rate of COVID-19 and $\eta_{1}, \eta_{2}, \eta_{3}$ are modification parameters where $1>\eta_{1}>\eta_{2}>\eta_{3} \geq 0$ which quantify the contribution of each infectious class compared to the most infectious ones. Thus, individuals that are symptomatic and not tested or isolated in class $I_{s}$ are more infectious than individuals in class $I_{A T}$ and those in class $J$. Exposed individuals $E(t)$ will progress into the $I_{A}(t)$ and $I_{s}(t)$ at rates $\sigma(1-\epsilon)$ and $\sigma \epsilon$ respectively where $\sigma$ is the rate of progression and $\epsilon \in[0,1]$ is the proportion of individuals from $E(t)$ that develop symptoms. Due to mass testing, some 
medRxiv preprint doi: https://doi.org/10.1101/2020.09.01.20186288; this version posted September 3, 2020. The copyright holder for this preprint (which was not certified by peer review) is the author/funder, who has granted medRxiv a license to display the preprint in

It is made available under a CC-BY-NC-ND 4.0 International license .

individuals in $I_{A}(t)$ test positive and are required to self isolate progressing to the class $I_{A T}(t)$ with a probability rate of detection due to mass testing $\gamma$ and they can recover from the infection and move to the removed class $R$ at a rate $\omega$. Those in class $I_{s}(t)$ of symptomatic individuals either progress to mandatory isolation at a rate $\delta=\gamma+\phi$ or recover from the infection at rate $\zeta$. Here, $\phi$ is the isolation rate due to the individuals visiting the health care centres before mass testing detection and $\gamma$ is the probability rate of detection due to mass testing of $I_{s}$ population. They can also die due to COVID-19 induced death at a rate $d_{1}$. Individuals in the $I_{A T}(t)$ class can either progress to the mandatory isolation care centers after developing symptoms at a rate $p \delta$, where $p$ is the probability that an individual in $I_{A T}(t)$ develops symptoms. They can also recover at a rate $\alpha$ and move to $R$. Individuals in the $J$ class can either recover at a rate $\nu$ or die due to the virus at a rate $d_{2}$. The flow diagram of the model with the aforementioned assumptions is in Figure 2 and the governing equations are given by systems of equations (1).

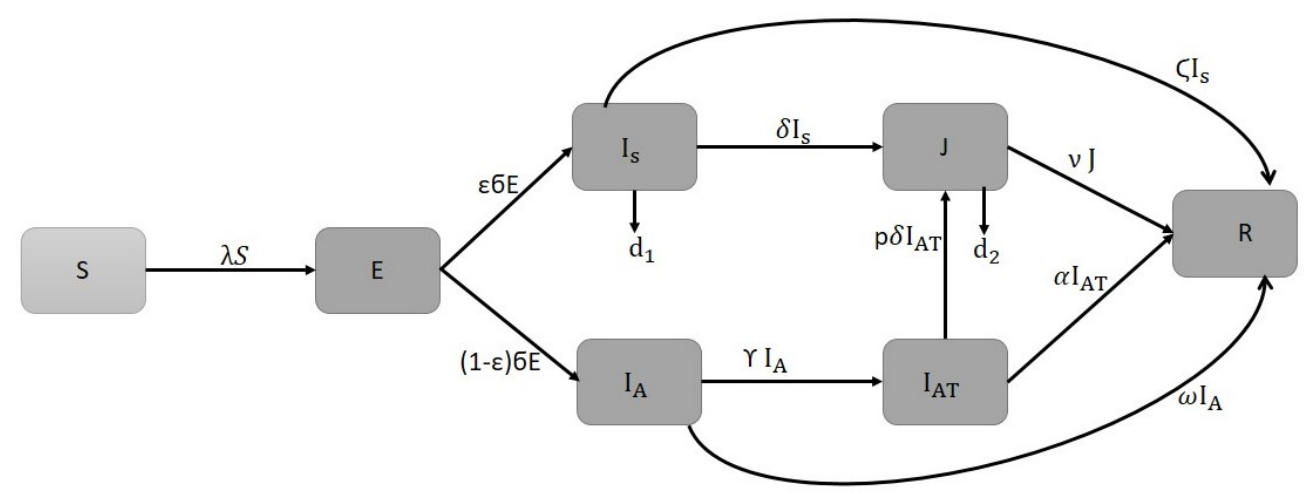

Fig. 2 Model flow diagram for the dynamics of COVID-19

$$
\begin{aligned}
& S^{\prime}(t)=-\lambda S(t), \\
& E^{\prime}(t)=\lambda S(t)-\sigma E(t), \\
& I_{A}^{\prime}(t)=\sigma(1-\epsilon) E(t)-(\omega+\gamma) I_{A}(t), \\
& I_{A T}^{\prime}(t)=\gamma I_{A}(t)-(p \delta+\alpha) I_{A T}(t), \\
& I_{s}^{\prime}(t)=\sigma \epsilon E(t)-\left(d_{1}+\zeta+\delta\right) I_{s}(t), \\
& J^{\prime}(t)=\delta I_{s}(t)+p \delta I_{A}(t)-\left(d_{2}+\nu\right) J(t), \\
& R^{\prime}(t)=\alpha I_{A T}(t)+\nu J(t)+\zeta I_{s}(t)+\omega I_{A}(t) .
\end{aligned}
$$

The model (1) has initial conditions given by

$$
S(0)=S_{0}>0, E(0)=E_{0} \geq 0, I_{A}(0)=I_{A 0} \geq 0, I_{A T}(0)=I_{A T 0} \geq 0,
$$


medRxiv preprint doi: https://doi.org/10.1101/2020.09.01.20186288; this version posted September 3, 2020. The copyright holder for this preprint (which was not certified by peer review) is the author/funder, who has granted medRxiv a license to display the preprint in

It is made available under a CC-BY-NC-ND 4.0 International license .

$I_{s}(0)=I_{s 0} \geq 0, J(0)=J_{0} \geq 0, R(0)=R^{0} \geq 0$ and based on biological considerations, all feasible solutions of model (1) exist in the region

$$
\Omega=\left\{\left(S(t), E(t), I_{A}(t), I_{A T}(t), I_{s}(t), J(t), R(t)\right) \in \mathcal{R}_{+}^{7} \mid 0<N(t) \leq N_{0}\right\}
$$

\section{Results}

\subsection{Mathematical results}

\subsubsection{Positivity and boundedness of solutions}

Model (1) describes dynamics of COVID-19 within the human population and therefore it is important and necessary to prove that all the variables used in the model $\left(S(t), E(t), I_{A}(t), I_{A T}(t), I_{s}(t), J(t), R(t)\right)$ are non-negative for all time and also that solutions for model system (1) with positive initial data will remain positive for all time and are bounded in $\Omega$.

Theorem 1 The solutions $\left(S(t), E(t), I_{A}(t), A T(t), I_{s}, J(t), R(t)\right)$ of model (1) with nonnegative intial conditions are positive for all $t \geq 0$.

Proof Solving the first equation of model system (1) using the separation of variables method we have

$$
\ln S(t)=-\int_{0}^{t} \lambda(s) d s
$$

which simplifies to

$$
S(t)=S_{0} e^{-\int_{0}^{t} \lambda(s) d s}>0 \quad \forall t \geq 0 .
$$

It is easy to follow a similar analysis to show that the other state variables $E(t), I_{A}(t), I_{A T}(t), I_{s}(t), J(t), R(t)$ are non-negative for all $t>0$. Based on this we conclude that the solutions of model system (1) remain positive for all $t \geq 0$ and this completes the proof.

Theorem 2 All solutions $\left(S(t), E(t), I_{A}(t), I_{A T}(t), I_{s}(t), J(t), R(t)\right) \in \mathcal{R}_{+}^{7}$ of model system (1) are bounded in $\Omega$.

Proof Considering the total population for model system (1) $N(t)$ we have

$$
\frac{d N}{d t}=-\left(d_{1} I_{s}+d_{2} J\right) \leq 0
$$

by the positivity of $I_{s}$ and $J$. The solution to the differential inequality using intial conditions $N(0)=N_{0}$ is given by

$$
N \leq N_{0}
$$

Hence, we conclude that $N(t)$ is bounded above and all state variables are bounded.

The region $\Omega$, in which the solutions of model system (1) are restricted is therefore a feasible region. 


\subsubsection{Equilibrium analysis and the Reproduction number}

The disease free equilibrium point is given by

$$
E_{0}=\left(N_{0}, 0,0,0,0,0,0\right) .
$$

Using the next generation matrix approach by [29], our model satisfy the conditions $A 1$ to $A 5$ and the basic reproduction number $\mathcal{R}_{0}$ is given by

$$
\mathcal{R}_{0}=\mathcal{R}_{S}+\mathcal{R}_{A}+\mathcal{R}_{A T}+\mathcal{R}_{J}
$$

where

$$
\begin{gathered}
\mathcal{R}_{S}=\frac{\beta \epsilon}{h}, \quad \mathcal{R}_{A}=\frac{\beta \eta_{1}(1-\epsilon)}{f}, \quad \mathcal{R}_{A T}=\frac{\beta \eta_{2} \gamma(1-\epsilon)}{f g}, \quad \mathcal{R}_{J}=\frac{\beta \eta_{3}(\gamma h p \delta(1-\epsilon)+f g \delta \epsilon)}{f g h k}, \\
f=(\omega+\gamma), g=(p \delta+\alpha), h=\left(\zeta+d_{1}+\delta\right), k=\left(\nu+d_{2}\right) .
\end{gathered}
$$

$\mathcal{R}_{S}$ is a local reproduction number that measures the secondary infections that arise when the index case is a symptomatic infectious individual, $\mathcal{R}_{S}$ is a local reproduction number that measures the secondary infections that arise when the index case is an asymptomatic infectious individual not tested, $\mathcal{R}_{A T}$ is a local reproduction number that measures the secondary infections that arise when the index case is an asymptomatic infectious individual who has been tested and self isolating and $\mathcal{R}_{J}$, is a local reproduction number that measures the secondary infections that arise when the index case is an isolated infectious individual.

It follows from the fact that the model satisfy conditions $A 1$ to $A 5$ of [29] that the disease free equilibrium is stable when $\mathcal{R}_{0}<1$ and unstable when $\mathcal{R}_{0}>1$. Hence, the stability theorem below holds

Theorem 3 The disease free equilibrium point $E_{0}$ for model system (1) is locally asymptotically stable provided that $\mathcal{R}_{0}<1$.

\subsubsection{Final and peak size relation}

In relation to controlling the novel COVID-19 virus, isolation has been one of the major worldwide control measure with most countries enforcing lock downs to the general susceptible population and mandatory isolation for infected individuals. In epidemic modelling quantities such as the reproduction numbers $\mathcal{R}_{0}, \mathcal{R}_{e}$, peak size and final peak size of the epidemic, are important in providing epidemiologists with useful information on the effects of such control measures on the dynamics of infection within the population [13]. We consider an epidemic that started as a result of an infected visitor from outside the population. The population is a completely susceptible population of size $N \approx S_{0}$. We use Feng et al. [13] to calculate the peak size of the pandemic and the simple Kermack- Mckendrick model approach in the work by Fred Brauer [4] to calculate the final size relation for COVID-19 as shown below. The population is a completely susceptible population of size $N \approx S_{0}$. 
medRxiv preprint doi: https://doi.org/10.1101/2020.09.01.20186288; this version posted September 3, 2020. The copyright holder for this preprint (which was not certified by peer review) is the author/funder, who has granted medRxiv a license to display the preprint in

It is made available under a CC-BY-NC-ND 4.0 International license .

Peak size relation

To determine the peak of the epidemic we define a weighted infected sum $y(t)$ as

$$
y(t)=E+\frac{\beta}{\mathcal{R}_{0}}\left[A I_{A}+B I_{A T}+C I_{s}+D J\right]
$$

where

$$
A=\frac{\eta_{1}}{f}+\frac{\gamma \eta_{2}}{f g}+\frac{p \delta \gamma \eta_{3}}{f g h}, \quad B=\frac{\eta_{2}}{g}+\frac{\eta_{3} p \delta}{g h}, \quad C=\frac{1}{h}+\frac{\delta \eta_{3}}{h k}, \quad D=\frac{\eta_{3}}{k} .
$$

The infected compartments $E(t), I_{A}(t), I_{A T}(t), I_{s}(t)$ and $J(t)$ are considered since they contribute to the infection. Now differentiating (2) with respect to $t$ yields

$$
y^{\prime}(t)=E^{\prime} \frac{\beta}{\mathcal{R}_{0}}\left[A I_{A}^{\prime}+B I_{A T}^{\prime}+C I_{s}^{\prime}+D J^{\prime}\right]
$$

and substituting $E^{\prime}(t), I_{A}^{\prime}(t), I_{A T}^{\prime}(t), I_{s}^{\prime}(t)$ and $J^{\prime}(t)$ from system (1) into (4) and simplifying yields

$$
y^{\prime}=\frac{\beta S\left[I_{s}+\eta_{1} I_{A}+\eta_{2} I_{A T}+\eta_{3} J\right]}{N}\left(1-\frac{N}{S \mathcal{R}_{0}}\right)
$$

which is equivalent to

$$
y^{\prime}=\lambda S\left(1-\frac{N}{S \mathcal{R}_{0}}\right) .
$$

Hence, dividing $y^{\prime}(t)$ by $S^{\prime}(t)$ of model system (1) yields

$$
\frac{d y}{d s}=-1+\frac{N}{S \mathcal{R}_{0}}
$$

where $N=N_{0}$ is a constant considering the limiting population of $N$. Integrating (5) with initial conditions $y(0)=y_{0}$ and $S(0)=S_{0}$ gives

$$
y(t)-y_{0}=-S(t)+S_{0}+\frac{N}{\mathcal{R}_{0}} \ln S(t)-\frac{N}{\mathcal{R}_{0}} \ln S_{0}
$$

which simplifies to

$$
y(t)+S(t)-\frac{N}{\mathcal{R}_{0}} \ln S(t)=y_{0}+S_{0}-\frac{N}{\mathcal{R}_{0}} \ln S_{0}
$$

where $y_{0}=E_{0}+\frac{\beta}{\mathcal{R}_{0}}\left[A I_{A 0}+B I_{A T 0}+C I_{s 0}+D J_{0}\right]$. The maximum value of $y(t)$ at any time $t$ is the number of infective when $y^{\prime}(0)=0$, that is when $S=\frac{N}{\mathcal{R}_{0}}$. This is given by

$$
y_{\text {max }}=y_{0}+S_{0}-\frac{N}{\mathcal{R}_{0}}\left[1-\ln \left(\frac{N}{\mathcal{R}_{0} S_{0}}\right)\right]
$$

and this is obtained when $S=\frac{N}{\mathcal{R}_{0}}$ and $y=y_{\max }$ in equation (6) then it follows that equation (6) is the peak of the epidemic size. 
medRxiv preprint doi: https://doi.org/10.1101/2020.09.01.20186288; this version posted September 3, 2020. The copyright holder for this preprint (which was not certified by peer review) is the author/funder, who has granted medRxiv a license to display the preprint in

It is made available under a CC-BY-NC-ND 4.0 International license .

Final size relation

To determine the final size relation of the basic reproduction number and the size of the epidemic, we take $S_{0}=N$ and $S_{\infty}$ to be a non-negative smooth decreasing function that tends to a limit as $t \rightarrow \infty$, i.e $S_{\infty}>0$. Using the Kermack-Mckendrick model approach [4], let

$$
\left(E_{\infty} \rightarrow 0, I_{A \infty} \rightarrow 0, I_{A T \infty} \rightarrow 0, I_{s \infty} \rightarrow 0, J_{\infty} \rightarrow 0\right) .
$$

Adding the first two equations and, also the first three equations of system of equations (1), we obtain

$$
(S+E)^{\prime}=-\sigma E .
$$

Integrating equation $(7)$ on $[0, \infty)$, we obtain

$$
S_{\infty}+E_{\infty}-S_{0}-E_{0}=-\sigma \int_{0}^{\infty} E(s) d s
$$

but $S_{0}=N, E_{\infty}=0$ hence we have

$$
\int_{0}^{\infty} E(s) d s=\frac{N-S_{\infty}}{\sigma}+\frac{E_{0}}{\sigma} .
$$

Integrating equation three of system equation(1) we have

$$
I_{A \infty}-I_{A 0}=\sigma(1-\epsilon) \int_{0}^{\infty} E(s) d s-f \int_{0}^{\infty} I_{A}(s) d s
$$

so

$$
\int_{0}^{\infty} I_{A}(s) d s=\frac{(1-\epsilon)}{f}\left(N-S_{\infty}\right)+\frac{(1-\epsilon)}{f} E_{0}+\frac{I_{A 0}}{f} .
$$

Similarly

$$
\int_{0}^{\infty} I_{A T}(s) d s=\frac{\gamma(1-\epsilon)}{f g}\left(N-S_{\infty}\right)+\frac{\gamma(1-\epsilon)}{f g} E_{0}+\frac{\gamma}{f g} I_{A 0}+\frac{I_{A T 0}}{g}
$$

and

$$
\int_{0}^{\infty} I_{s}(s) d s=\frac{\epsilon}{h}\left(N-S_{\infty}\right)+\frac{\epsilon}{h} E_{0}+\frac{I_{s 0}}{h}
$$

and also

$$
\begin{aligned}
\int_{0}^{\infty} J(s) d s & =\frac{p \delta \gamma(1-\epsilon)}{f g k}\left(N-S_{\infty}\right)+\frac{p \delta \gamma(1-\epsilon)}{f g k} E_{0}+\frac{\gamma p \delta}{f g k} I_{A 0}+\frac{p \delta}{g k} I_{A T 0} \\
& +\frac{\delta \epsilon}{k h}\left(N-S_{\infty}\right)+\frac{\epsilon \delta}{h k} E_{0}+\frac{\delta}{k h} I_{s 0}+\frac{J_{0}}{k}
\end{aligned}
$$

From the first equation of system (1) we have

$$
\frac{S^{\prime}}{S}=\frac{-\beta\left[I_{s}+\eta_{1} I_{A}+\eta_{2} I_{A T}+\eta_{3} J\right]}{N} .
$$


Therefore, integrating $(12)$ on $[0, \infty)$ yields

$$
\ln S_{0}-\ln S_{\infty}=\frac{\beta}{N}\left[\int_{0}^{\infty} I_{s} d s+\eta_{1} \int_{0}^{\infty} I_{A} d s+\eta_{2} \int_{0}^{\infty} I_{A T} d s+\eta_{3} \int_{0}^{\infty} J d s\right]
$$

and hence substituting (8)-(11) into (13) and simplifying yields

$$
\frac{\ln S_{0}}{S_{\infty}}=\frac{\mathcal{R}_{0}}{N}\left(N-S_{\infty}\right)+\frac{\mathcal{R}_{0}}{N} y_{0}
$$

where $y_{0}=E_{0}+\frac{\beta}{\mathcal{R}_{0}}\left[A I_{A 0}+B I_{A T 0}+C I_{s 0}+D J_{0}\right]$. Therefore equation (14) gives the final size relation with initial terms $I_{s 0}, E_{0}, I_{A 0}, I_{A T 0}$ and $J_{0}$. If the initial terms are assumed to be $E(0)=I_{A}(0)=I_{A T}(0)=I_{s}(0)=J(0)=0$, and if a small number of infectives are introduced into the population then we have $S_{0} \approx N_{0}$ such that the final size relation has the form

$$
\frac{\ln S_{0}}{S_{0}}=\frac{\mathcal{R}_{0}}{N}\left(1-\frac{S_{\infty}}{N_{0}}\right) .
$$

Equation (15) can be simplified further to give

$$
S_{\infty}=S_{0} \exp \mathcal{R}^{\mathcal{R}_{0}}\left(1-\frac{S_{\infty}}{N_{0}}\right),
$$

therefore $\left(1-\frac{S_{\infty}}{N_{0}}\right)$ is the clinical attack rate and $\left(S_{0}-S_{\infty}\right)$ is the size of the epidemic (that is the number of individuals in the population who are infected over the course of the epidemic).

\section{Global stability analysis of the disease free equilibrium}

Theorem 4 The disease free equilibrium for models system (1) is globally asymptotically stable provided that $\mathcal{R}_{0}<1$.

Proof In order to prove the above theorem we construct a Lyapunov function as follows

$$
\begin{aligned}
\mathcal{L} & =\left[\frac{\eta_{1}(1-\epsilon)}{f}+\frac{\gamma \eta_{2}(1-\epsilon)}{f g}+\frac{\epsilon}{h}+\frac{\eta_{3}(\gamma p \delta h(1-\epsilon)+\delta g \epsilon f)}{f g h k}\right] E+A I_{A}+B I_{A T} \\
& +C I_{s}+D J
\end{aligned}
$$

where $A, B, C$ and $D$ are defined in equation (3). Differentiating $\mathcal{L}$ yields

$$
\begin{aligned}
\mathcal{L}^{\prime} & =\left[\frac{\eta_{1}(1-\epsilon)}{f}+\frac{\gamma \eta_{2}(1-\epsilon)}{f g}+\frac{\epsilon}{h}+\frac{\eta_{3}(\gamma p \delta h(1-\epsilon)+\delta g \epsilon f)}{f g h k}\right] E^{\prime}+A I_{A}^{\prime}+B I_{A T}^{\prime} \\
& +C I_{s}^{\prime}+D J^{\prime}
\end{aligned}
$$


medRxiv preprint doi: https://doi.org/10.1101/2020.09.01.20186288; this version posted September 3, 2020. The copyright holder for this preprint (which was not certified by peer review) is the author/funder, who has granted medRxiv a license to display the preprint in

It is made available under a CC-BY-NC-ND 4.0 International license .

which simplifies to

$$
\begin{aligned}
\mathcal{L}^{\prime} & =\left[\frac{\eta_{1}(1-\epsilon)}{f}+\frac{\gamma \eta_{2}(1-\epsilon)}{f g}+\frac{\epsilon}{h}+\frac{\eta_{3}(\gamma p \delta h(1-\epsilon)+\delta g \epsilon f)}{f g h k}\right][\lambda S-\sigma E]+A[\sigma(1-\epsilon) E \\
& \left.-f I_{A}\right]+B\left[\gamma I_{A}-g I_{A T}\right]+C\left[\sigma \epsilon E-h I_{s}\right]+D\left[\delta I_{s}+p \delta I_{A T}-k J\right] .
\end{aligned}
$$

Therefore expanding (16) and simplifying with the definition of $A, B, C$ and $D$ in equation (3) yields

$$
\begin{aligned}
\mathcal{L}^{\prime} & =\left[\frac{\eta_{1}(1-\epsilon)}{f}+\frac{\gamma \eta_{2}(1-\epsilon)}{f g}+\frac{\epsilon}{h}+\frac{\eta_{3}(\gamma p \delta h(1-\epsilon)+\delta g \epsilon f)}{f g h k}\right] \frac{\beta\left[I_{s}+\eta_{1}+\eta_{2} I_{A T}+\eta_{3} J\right]}{N} \\
& -I_{s} \\
& -\eta_{1} I_{A}-\eta_{2} I_{A T}-\eta_{3} J .
\end{aligned}
$$

Using the definition of $\mathcal{R}_{0}$ this further simplifies to

$$
\begin{aligned}
\mathcal{L}^{\prime} & =\frac{\mathcal{R}_{0} S}{N}\left[I_{s}+\eta_{1} I_{A}+\eta_{2} I_{A T}+\eta_{3} J\right]-I_{s}-\eta_{1} I_{A}-\eta_{2} I_{A T}-\eta_{3} J \\
& =\left(\frac{\mathcal{R}_{0} S}{N}-1\right)\left[I_{s}+\eta_{1} I_{A}+\eta_{2} I_{A T}+\eta_{3} J\right]
\end{aligned}
$$

but $\frac{S}{N} \leq 1$ in the domain such that it follows that

$$
\mathcal{L}^{\prime} \leq\left(\mathcal{R}_{0}-1\right)\left[I_{s}+\eta_{1} I_{A}+\eta_{2} I_{A T}+\eta_{3} J\right],
$$

therefore is $\mathcal{R}_{0}<1$, then it follows that $\mathcal{L} \leq 0$. It also follows that when $E(t)=$ $I_{A}(t)=I_{A T}(t)=I_{s}(t)=J(t)=0, \mathcal{L} \leq 0$ and hence the largest compact invariant set is the singleton $\left\{E_{0}\right\}$. Therefore by LaSalle's invariance principle it follows that $E_{0}$ is globally asymptotically stable in $\Omega$. This completes the proof.

Numerical simulations results

We present simulations to assess the potential impact of isolation and mass testing on COVID-19 by fitting the model to cumulative cases in Nigeria. Data on cumulative cases was obtained from official public sources from the Nigeria government [11]. Our simulations will focus on two parameters $\gamma$ which is the mass testing parameter and $\eta_{2}$ the measures of the impact of contribution of the asymptomatic self-isolating population. The testing parameter $\gamma$ assumes the values $0,0.0261$ and 0.0496 . The value zero represents absence of mass testing after day 87, The value 0.0261 represents the baseline fitted value which we take as the base testing level by day 87 and the value 0.0496 represents an increase of testing level after day 87 . The parameter $\eta_{2}$ assumes the value 0.5391 as the baseline fitted value. $\eta_{2}=0$ represents no transmission of COVID-19 by self-isolating individuals after day 87 and $\eta_{2}=0.0539$ 
represents reduced transmission rate of COVID-19 from the baseline contribution. Figures 7, 8 and 9 show the model projections for COVID-19 from day one of infection up to day 365 . The pair $\left(\gamma, \eta_{2}\right)=(0,0)$ is a scenario where the mass testing is stopped and no transmission from self-isolating individuals after day 87 and $\left(\gamma, \eta_{2}\right)=(0.0496,0.0539)$ is a scenario with increased mass testing and reduced transmission from self-isolating individuals after day 87 whilst $\left(\gamma, \eta_{2}\right)=(0.0261,0.5391)$ is the baseline pair from data fitted to the model.

Table 1 Parameter values for the model with mass testing and isolation

\begin{tabular}{|c|c|c|}
\hline Parameter & Value & source \\
\hline$\beta$ & 0.9999 & fitted \\
$\eta_{1}, \eta_{2}, \eta_{3}$ & $0.9577,0.5391,0.9144$ & fitted \\
$\sigma$ & 0.9375 & fitted \\
$\omega$ & 1 & fitted \\
$\gamma$ & 0.0261 & fitted \\
$\epsilon$ & 0.0148 & fitted \\
$p$ & 0.0473 & fitted \\
$\phi$ & 0.0265 & fitted \\
$\alpha$ & 0.4927 & fitted \\
$\zeta$ & $5.1462 \mathrm{e}-04$ & fitted \\
$d_{1}$ & $4.1579 \mathrm{e}-04$ & fitted \\
$d_{2}$ & 0.0357 & fitted \\
$\nu$ & 0.0377 & fitted \\
\hline
\end{tabular}

Figure 3 shows the fit for cumulative cases for Nigeria from day one (1) of first infection recorded to day 87 of recorded infections. The model fit agrees relatively to the data and hence, we use the parameter values for this fit to make the projections on the impact of mass testing and isolation in Nigeria. The fitted parameter values are presented in Table 1.

Figure 4 shows the model projections for COVID-19 daily cases for asymptotic $\left(I_{A}\right)$, self-isolating $\left(I_{A T}\right)$, symptomatic $\left(I_{s}\right)$ and symptomatic isolated $(J)$ populations from day one of infection up to day 365 . If mass testing were to be stopped after day 87 , then more asymptomatic and symptomatic case would remain in the society and undetected. The increase in mass testing after day 87 was associated with a corresponding increase in detected cases and a reduction in undetected cases. Lower peaks of undetected cases were associated increase in mass testing with significant decrease in peak for symptomatic cases.

Figure 5 shows model projection for COVID-19 cumulative self-isolating, cumulative admissions from $I_{s}$, cumulative admissions from $I_{A T}$ and overall cumulative admissions for Nigeria from day one of infection up to day 365 . We observe that increasing mass testing is associated with increase in cumulative self isolation cases and as well as cumulative admissions of symptomatic cases especially from $I_{s}$ into monitored isolation centres.

Figure 6 shows the model projections for COVID-19 overall cumulative cases, cumulative cases from $I_{s}$, cumulative cases from $I_{A T}$ and cumulative 
medRxiv preprint doi: https://doi.org/10.1101/2020.09.01.20186288; this version posted September 3, 2020. The copyright holder for this preprint (which was not certified by peer review) is the author/funder, who has granted medRxiv a license to display the preprint in

It is made available under a CC-BY-NC-ND 4.0 International license .

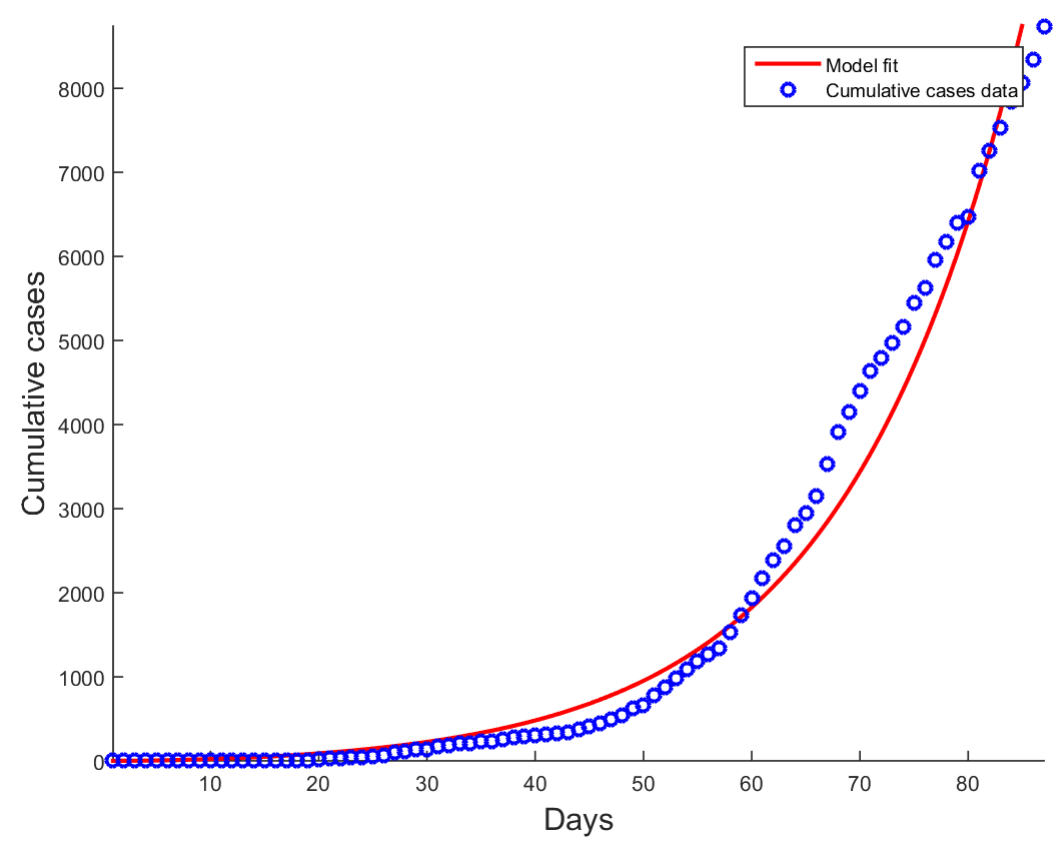

Fig. 3 Model fit for COVID-19 Cumulative cases for Nigeria since day one of infection to day 87 .

deaths for Nigeria from day one of infection up to day 365. The results show that the cumulative cases will reduce with the increase in mass testing. We also note that more cases will be recorded in the monitored isolation centres. Cumulative deaths will also decrease with increase in mass testing.

Figure 7 shows the model projections for COVID-19 daily cases for asymptotic, self-isolating, symptomatic and symptomatic isolated populations. The results reveal that better outcomes are achieved when there is increased mass testing and reduced transmission from those that are self-isolating. We also observe that the worst case resulted from stopping mass testing and no transmission from the self-isolating individuals. Figure 8, shows that increasing mass testing and reducing the transmission of self-isolating individuals would initially reduce the cumulative cases but there will be a switch with the baseline scenario. In Figure 9, the worst case which increases cumulative deaths over time is when there is no mass testing and no transmission from self-isolating individuals.

\section{Conclusion}

We presented a mathematical model for COVID-19 for Nigeria using the cumulative cases data to calibrate the model and used the fitted parameters 

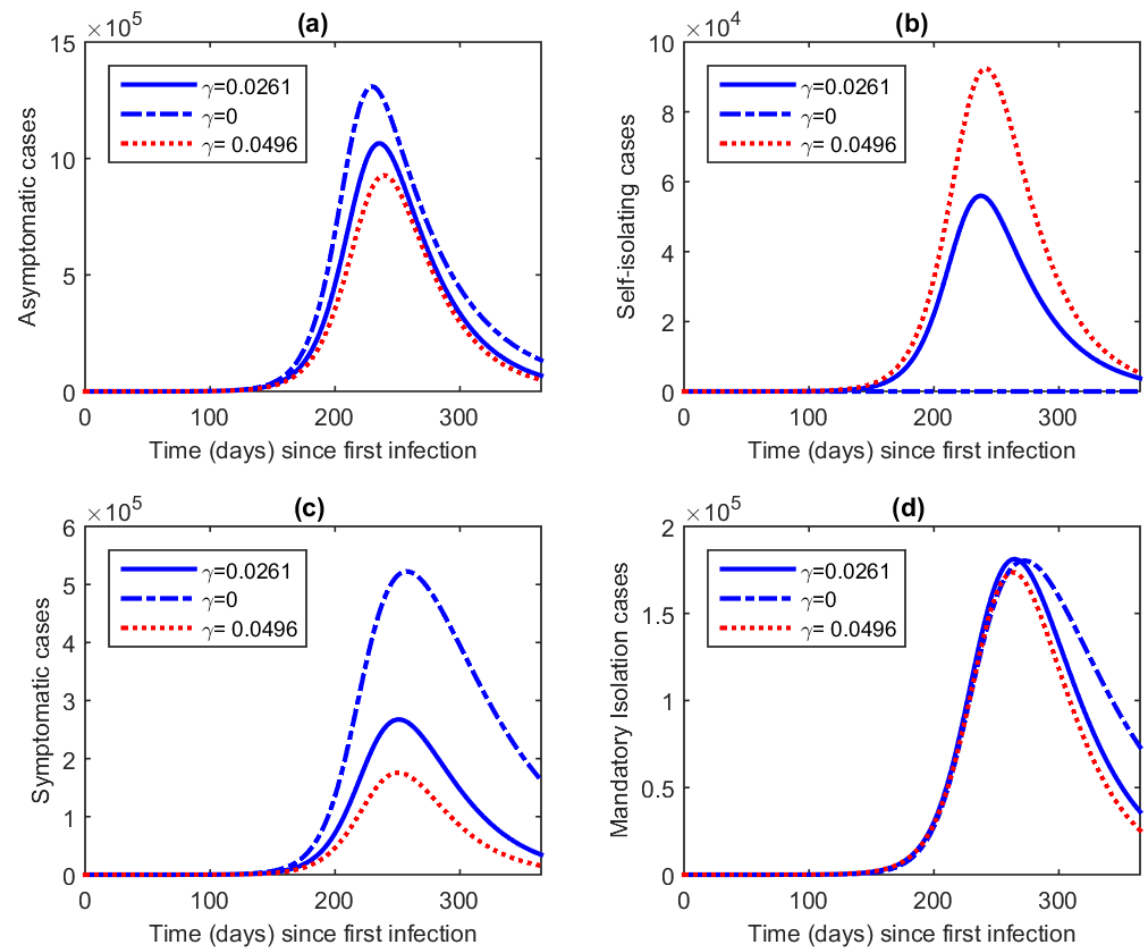

Fig. 4 Model projection for COVID-19 daily cases for asymptotic, self-isolating, symptomatic and symptomatic isolated populations from day one of infection up to day 365 .

as baseline parameters for model predictions. Mathematical analysis was done and important thresholds for model that can be used to predict the progression or non-progression of the infection in a population. Our results suggest that increase in mass testing is associated with benefits of increasing detected cases, lowering peaks of symptomatic cases, increase in self-isolating cases, decrease in cumulative deaths and decrease in admissions into monitored isolation facilities. If used in combination with monitoring the contact of self-isolating individuals, better benefits are realised when increase in mass testing is done with low transmission rate from the self-isolating individuals but the benefits are short-lived. The worst scenario comes from the case when mass testing is stopped and no transmission from the already self-isolating cases for this is associated with increase in the burden of COVID-19. From our results, we draw the following conclusion: Mass testing is important in exposing asymptomatic cases which should self-isolate and minimize if not have zero transmission. Further, the exposition of these self-isolation cases in turn is associated with lowering of peaks and less clogging of monitored isolation centres as well as the reduction of fatalities. The current mass testing levels in Nigeria have not yet realised these benefits and more efforts should be invested in these strategies to help its health system to manage the worst case scenarios. Lock down mea- 
medRxiv preprint doi: https://doi.org/10.1101/2020.09.01.20186288; this version posted September 3, 2020. The copyright holder for this preprint (which was not certified by peer review) is the author/funder, who has granted medRxiv a license to display the preprint in

It is made available under a CC-BY-NC-ND 4.0 International license .
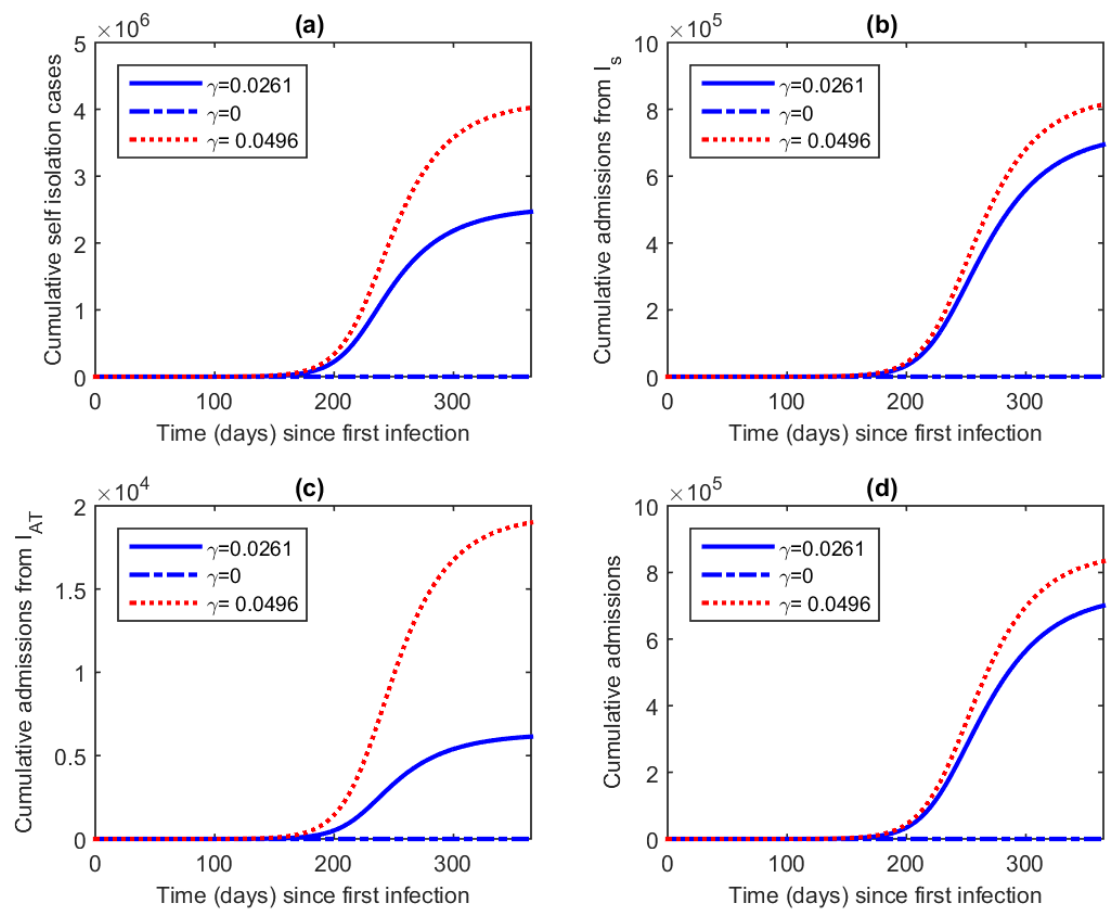

Fig. 5 Model projection for COVID-19 cumulative self-isolating, cumulative admissions from $I_{s}$, cumulative admissions from $I_{A T}$ and overall cumulative admissions for Nigeria from day one of infection up to day 365.

sures associated with physical distancing have been shown to delay the peaks and help systems prepare for the worst [23] but they fall short of identifying the potential threat imposed by various infectious groups. The current study has been been able to show similar benefits as the lock down measures but more importantly the specific target groups that could be the silent drivers of infection. With the setup of most under-privileged communities in Nigeria, its impossible to have zero transmission and hence, the strategy of mass testing and isolation should be complemented with other various COVID-19 preventive, management and administrative strategies. Results from this study can easily be adapted to any other country with variables similar to the modelling framework in this study.

Acknowledgements FC would like to thank his institution for the URC grant and material support that enabled the completion of this project.

\section{Conflict of interest}

The authors declare that they have no conflict of interest. 
medRxiv preprint doi: https://doi.org/10.1101/2020.09.01.20186288; this version posted September 3, 2020. The copyright holder for this preprint (which was not certified by peer review) is the author/funder, who has granted medRxiv a license to display the preprint in
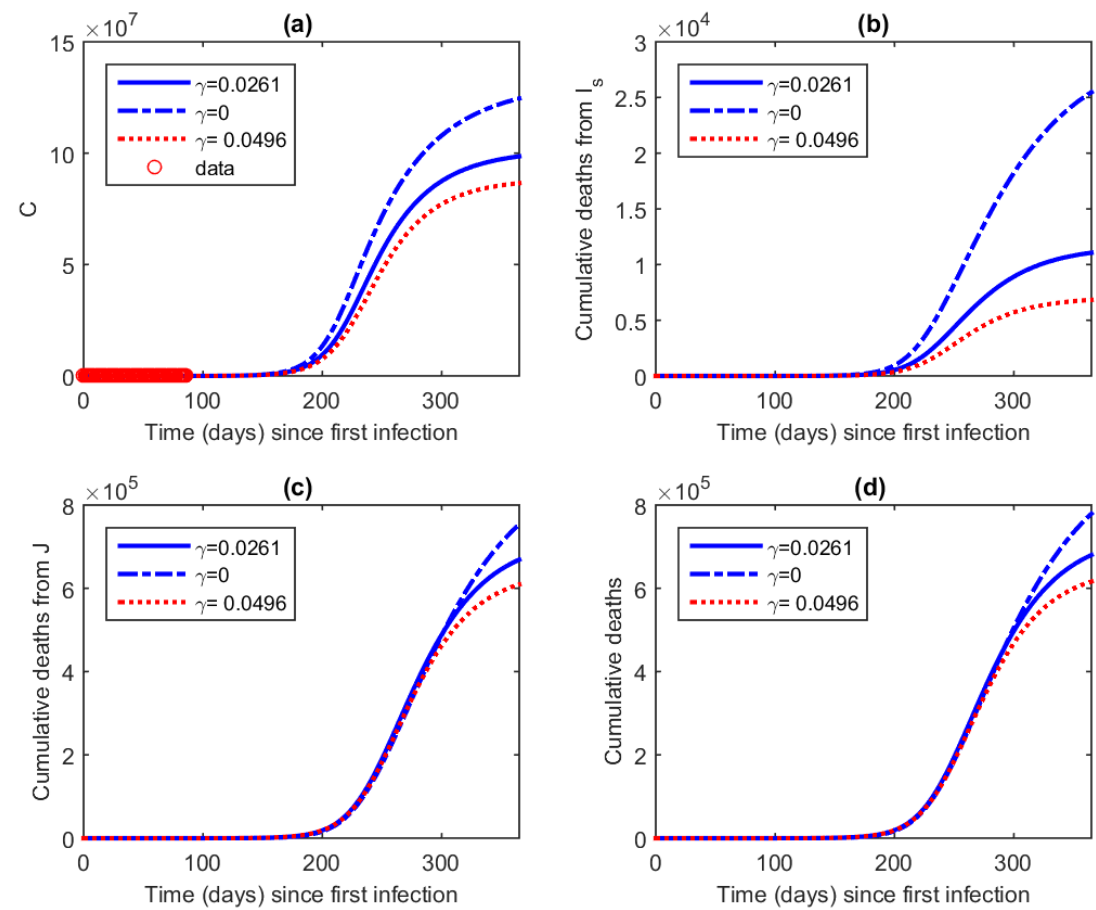

Fig. 6 Model projection for COVID-19 overall cumulative cases, cumulative cases from $I_{s}$, cumulative cases from $I_{A T}$ and cumulative deaths for Nigeria from day one of infection up to day 365.
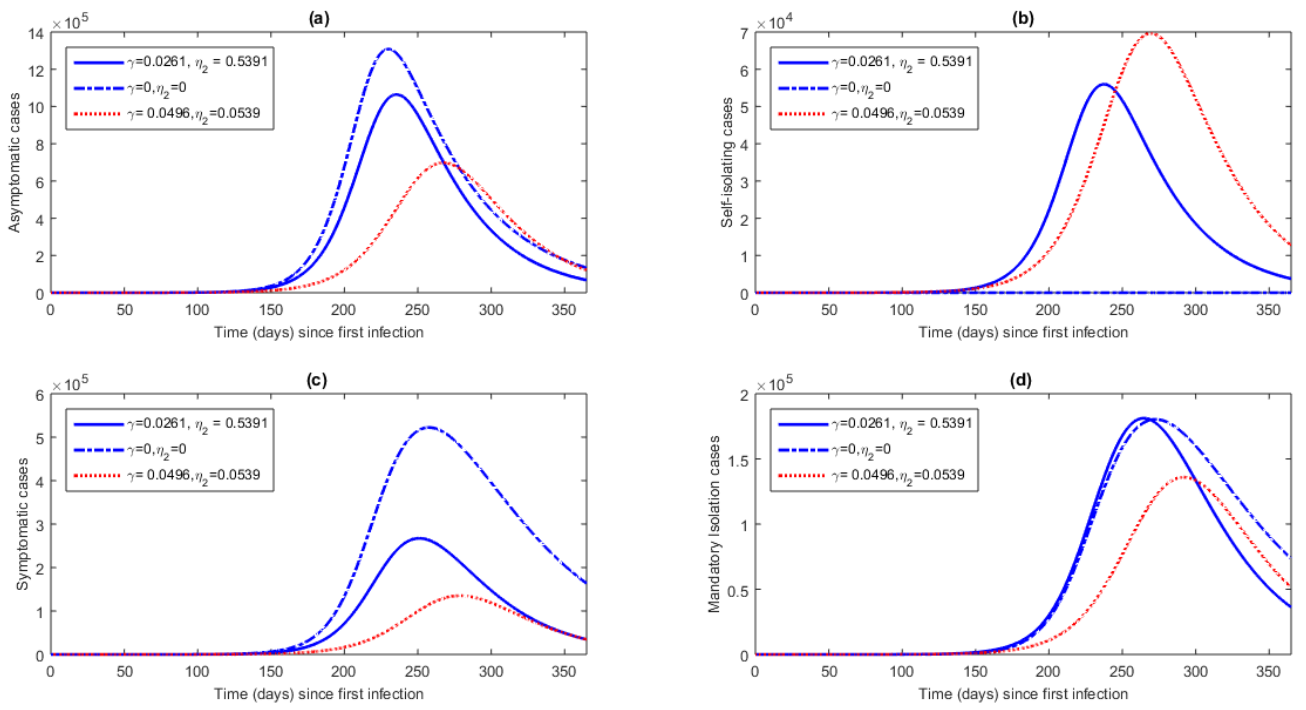

Fig. 7 Model projection for COVID-19 daily cases for asymptotic, self-isolating, symptomatic and symptomatic isolated populations from day one of infection up to day 365 . 
medRxiv preprint doi: https://doi.org/10.1101/2020.09.01.20186288; this version posted September 3, 2020. The copyright holder for this preprint (which was not certified by peer review) is the author/funder, who has granted medRxiv a license to display the preprint in

It is made available under a CC-BY-NC-ND 4.0 International license .
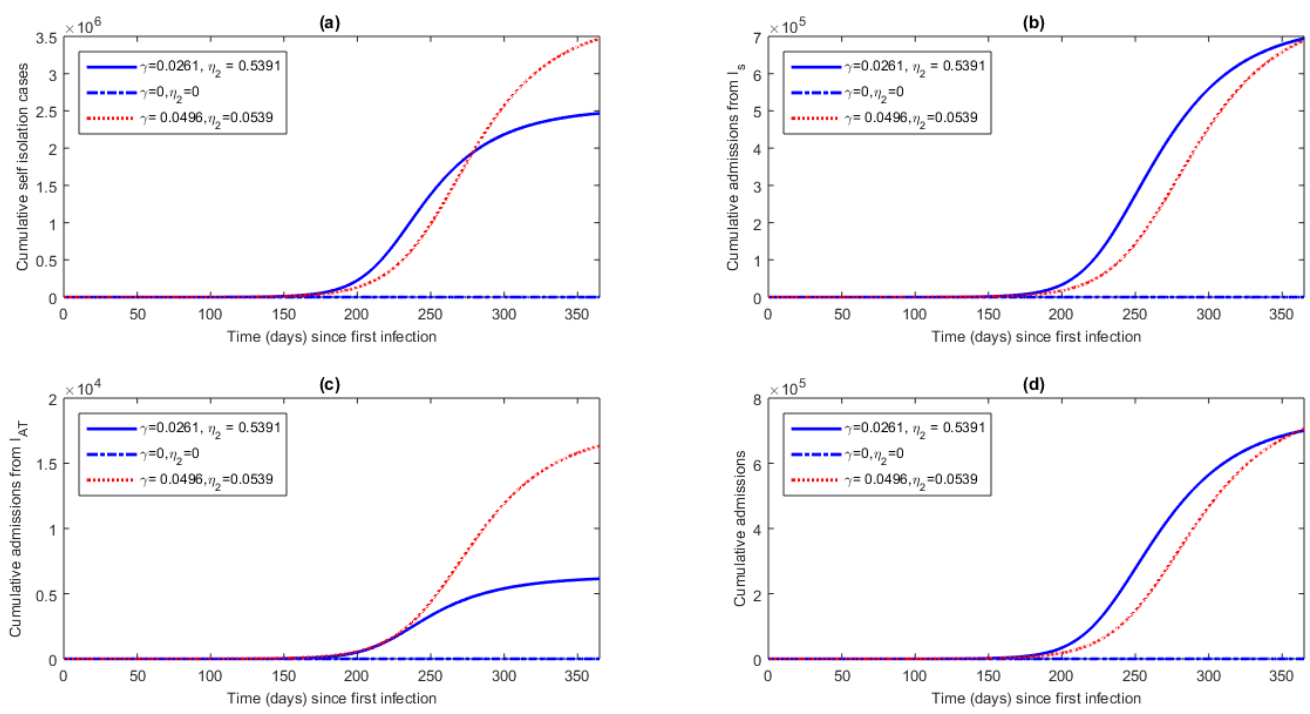

Fig. 8 Model projection for COVID-19 cumulative self-isolating, cumulative admissions from $I_{s}$, cumulative admissions from $I_{A T}$ and overall cumulative admissions for Nigeria from day one of infection up to day 365 .
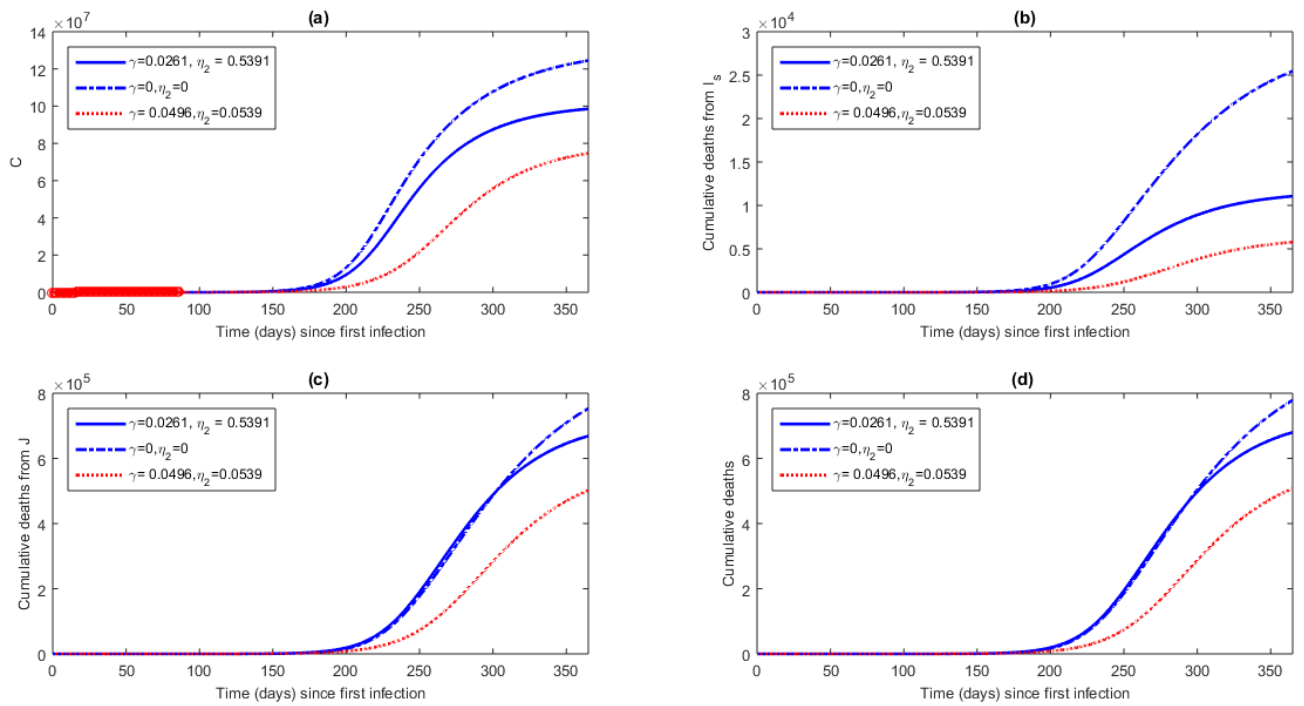

Fig. 9 Model projection for COVID-19 overall cumulative cases, cumulative cases from $I_{s}$, cumulative cases from $I_{A T}$ and cumulative deaths for Nigeria from day one of infection up to day 365 . 


\section{References}

1. Nigeria to ease lockdowns in major cities. BBC News https://www.bbc.com/news/worldafrica-52445414. Accessed on 22nd August 2020. (2020).

2. Ahmad, T., Khan, M., Haroon, T. H. M., Nasir, S., Hui, J., Bonilla-Aldana, D. K., And Rodriguez-Morales, A. J. Covid-19: Zoonotic aspects. Travel Medicine and Infectious Disease (2020).

3. Black, J. R., Bailey, C., and Swanton, C. Covid-19: the case for health-care worker screening to prevent hospital transmission. The Lancet (2020).

4. Brauer, F. Early estimates of epidemic final sizes. Journal of biological dynamics 13, sup1 (2019), 23-30.

5. CaO, J., JiAng, X., Zhao, B., Et Al. Mathematical modeling and epidemic prediction of covid-19 and its significance to epidemic prevention and control measures. J BioMed Res Innov 1, 1 (2020), 103.

6. Carcione, J. M., Santos, J. E., Bagaini, C., And Ba, J. A simulation of a covid-19 epidemic based on a deterministic seir model. arXiv preprint arXiv:2004.03575 (2020).

7. Cetron, M., and Landwirth, J. Public health and ethical considerations in planning for quarantine. The Yale journal of biology and medicine 78, 5 (2005), 329.

8. Checchi, F. Response strategies for covid-19 epidemics in african settings: a mathematical modelling study.

9. Chen, T.-M., Rui, J., Wang, Q.-P., Zhao, Z.-Y., Cui, J.-A., And Yin, L. A mathematical model for simulating the phase-based transmissibility of a novel coronavirus. Infectious diseases of poverty 9, 1 (2020), 1-8.

10. Cortegiani, A., Ingoglia, G., Ippolito, M., Giarratano, A., and Einav, S. A systematic review on the efficacy and safety of chloroquine for the treatment of covid19 [published online march 10, 2020]. J Crit Care. doi 10.

11. COVID, N. 19 nigeria. Nigeria Centre for Disease Control. Available online: https://covid19. ncdc. gov. ng/(accessed on 22 August 2020) (2020).

12. Embassy, U. COVID-19 Information. http://ng.usembassy.gov/u-s-citizenservices/covid-19-information/. Accessed on 22nd August 2020. (2020).

13. FEnG, Z. Final and peak epidemic sizes for seir models with quarantine and isolation. Mathematical Biosciences \& Engineering 4, 4 (2007), 675-686.

14. Gumel, A. B., Ruan, S., Day, T., Watmough, J., Brauer, F., Van den Driessche, P., Gabrielson, D., Bowman, C., Alexander, M. E., Ardal, S., et Al. Modelling strategies for controlling sars outbreaks. Proceedings of the Royal Society of London. Series B: Biological Sciences 271, 1554 (2004), 2223-2232.

15. Ivorra, B., Ferrández, M., Vela-Pérez, M., and Ramos, A. Mathematical modeling of the spread of the coronavirus disease 2019 (covid-19) considering its particular characteristics. the case of china. Tech. rep., Technical report, MOMAT, 03 2020. URL: https://doi-org. usm. idm. oclc. org . . , 2020.

16. Khan, M. A., And Atangana, A. Modeling the dynamics of novel coronavirus (2019ncov) with fractional derivative. Alexandria Engineering Journal (2020).

17. Kucharski, A. J., Russell, T. W., Diamond, C., Liu, Y., Edmunds, J., Funk, S., Eggo, R. M., Sun, F., Jit, M., Munday, J. D., Et Al. Early dynamics of transmission and control of covid-19: a mathematical modelling study. The lancet infectious diseases (2020).

18. Li, X., Geng, M., Peng, Y., Meng, L., And Lu, S. Molecular immune pathogenesis and diagnosis of covid-19. Journal of Pharmaceutical Analysis (2020).

19. Lin, Q., Zhao, S., Gao, D., Lou, Y., Yang, S., Musa, S. S., Wang, M. H., Cai, Y., WANG, W., YANG, L., ET AL. A conceptual model for the coronavirus disease 2019 (covid-19) outbreak in wuhan, china with individual reaction and governmental action. International journal of infectious diseases 93 (2020), 211-216.

20. López, L., AND Rodo, X. A modified seir model to predict the covid-19 outbreak in spain and italy: simulating control scenarios and multi-scale epidemics. Available at SSRN 3576802 (2020).

21. NCDC. Nigeria Centre for Disease Control. https://ncdc.gov.ng/diseases/sitreps/.Accessed on 22nd April 2020. (2020). 
22. Nicola, M., O’Neill, N., Sohrabi, C., Khan, M., Agha, M., and Agha, R. Evidence based management guideline for the covid-19 pandemic-review.

23. Nyabadza, F., Chirove, F., Chukwu, W. C., and Visaya, M. V. Modelling the potential impact of social distancing on the covid-19 epidemic in south africa. medRxiv (2020).

24. Prem, K., Liu, Y., Russell, T. W., Kucharski, A. J., Eggo, R. M., Davies, N., Flasche, S., Clifford, S., Pearson, C. A., Munday, J. D., Et al. The effect of control strategies to reduce social mixing on outcomes of the covid-19 epidemic in wuhan, china: a modelling study. The Lancet Public Health (2020).

25. Rodriguez-Morales, A. J., Cardona-Ospina, J. A., Gutiérrez-Ocampo, E., Villamizar-Peña, R., Holguin-Rivera, Y., Escalera-Antezana, J. P., AlvaradoArnez, L. E., Bonilla-Aldana, D. K., Franco-Paredes, C., Henao-Martinez, A. F., ET AL. Clinical, laboratory and imaging features of covid-19: A systematic review and meta-analysis. Travel medicine and infectious disease (2020), 101623.

26. Rothan, H. A., And Byrareddy, S. N. The epidemiology and pathogenesis of coronavirus disease (covid-19) outbreak. Journal of autoimmunity (2020), 102433.

27. Sohrabi, C., Alsafi, Z., O'Neill, N., Khan, M., Kerwan, A., Al-Jabir, A., Iosifidis, C., AND AGHA, R. World health organization declares global emergency: A review of the 2019 novel coronavirus (covid-19). International Journal of Surgery (2020).

28. Studdert, D. M., And Hall, M. A. Disease control, civil liberties, and mass testing - calibrating restrictions during the covid-19 pandemic. New England Journal of Medicine (2020).

29. Van den Driessche, P., And Watmough, J. Reproduction numbers and sub-threshold endemic equilibria for compartmental models of disease transmission. Mathematical biosciences 180, 1-2 (2002), 29-48.

30. VANGUARDNGR. Who qualifies for covid-19 testing in nigeria? Available online: https://www.vanguardngr.com/2020/04/who-qualifies-for-covid-19-testing-innigeria/accessed on 22 August 2020) (2020).

31. WAng, L.-S., Wang, Y.-R., Ye, D.-W., AND LiU, Q.-Q. A review of the 2019 novel coronavirus (covid-19) based on current evidence. International journal of antimicrobial agents (2020), 105948.

32. WANG, M., AND QI, J. A deterministic epidemic model for the emergence of covid-19 in china. medRxiv (2020).

33. Wilder-Smith, A., Chiew, C. J., And Lee, V. J. Can we contain the covid-19 outbreak with the same measures as for sars? The Lancet Infectious Diseases (2020).

34. Wilder-Smith, A., ANd Freedman, D. O. Isolation, quarantine, social distancing and community containment: pivotal role for old-style public health measures in the novel coronavirus (2019-ncov) outbreak. Journal of travel medicine 27, 2 (2020), taaa020.

35. WORLDOMETER. Worldometer, nigeria population 2020 https://www.worldometers.info/world-population/nigeria-population/. Accessed on 1st August 2020. (2020).

36. Yang, J., Zheng, Y., Gou, X., Pu, K., Chen, Z., Guo, Q., Ji, R., Wang, H., Wang, Y., AND ZHOU, Y. Prevalence of comorbidities and its effects in patients infected with sars-cov-2: a systematic review and meta-analysis. International Journal of Infectious Diseases 94 (2020), 91. 